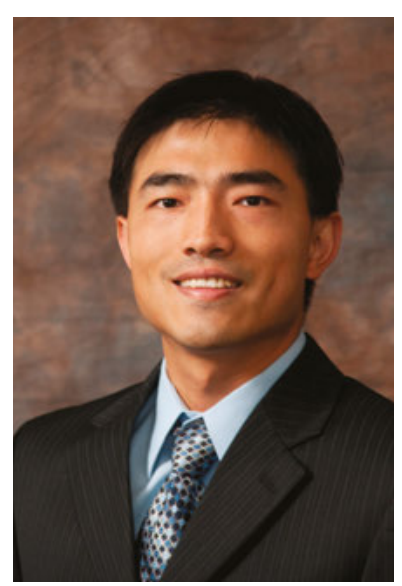

creativity and scientific scholarship in several areas of materials science.

Professor Yu has made significant contributions to synthesis and fundamental investigation of new multifunctional polymer nanostructures with novel chemical and physical properties, and their significant applications in advanced energy, sustainability and environmental technologies. A rising leader in the field of polymer science, he has authored over 150 articles in peer-reviewed journals and his work has garnered more than 19,000 citations, with 21 articles having each received over 200 citations. The work of his research group has been featured in prominent journals and global scientific news.

Professor $\mathrm{Yu}$ will give a lecture and receive this award at the World Polymer Congress (http://www. macro2020.org/), which will be held in Jeju Island, South Korea, 5-9 July 2020. The award includes $\$ 5,000$, plus travel and hotel accommodation expenses to attend MACRO 2020.

https://iupac.org/7th-polymer-international-iupac-award-goes-toguihua-yu/

\section{IUPAC-ThalesNano Prize In Flow Chemistry and Microfluidics-Call For Nominations}

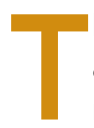

he IUPAC-ThalesNano Prize in Flow Chemistry and Microfluidics is to be awarded to an internationally recognized scientist, whose activities or published accounts have made an outstanding contribution in the field of flow chemistry, microfluidics, micro fabrication, and micro systems engineering in academia or industry. Nomination materials should be submitted by 31 May 2020 by visiting the website.

https://iupac.org/2020-iupac-thalesnano-prize-in-flow-chemistry-andmicrofluidics-call-for-nominations/

\section{Advancing Science as a Global Public Good: ISC Action Plan 2019-2021}

\section{he International Science Council's (ISC) released a new action plan for action over the next two and a half years. The document most important purpose is to form a practical framework for the ISC's work, in all of its key functions, until the end of 2021.}

The Action plan gives effect to the Council's vision and mission, contained in the high-level strategy published on the occasion of the Council's launch in 2018. In addition, it serves as a basis for active engagement with ISC members, and as a point of departure for dialogue and cooperation with partners and funders who share our objectives. The Action Plan is intended to be a living document, allowing the ISC the flexibility to respond

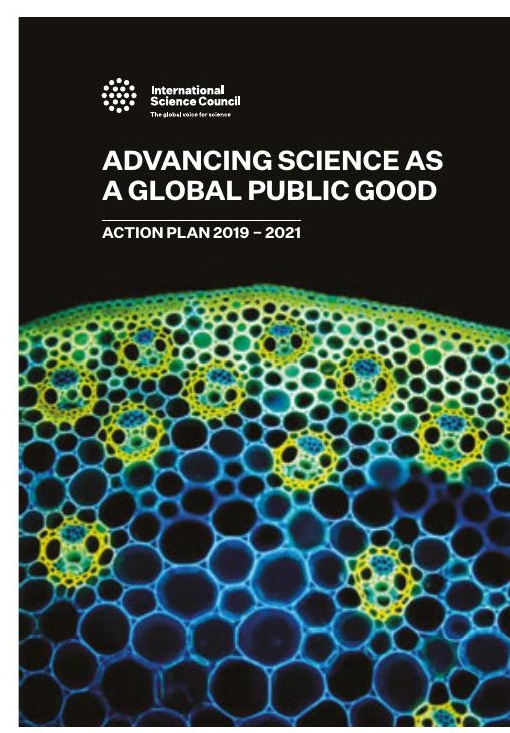
to new and emerging opportunities, and to adapt to ongoing strategic reflection and development. It will also provide a basis for continual monitoring and progress reporting to members and other stakeholders.

At the heart of the Action Plan is a selection of projects and programmes that are relevant to all scientific fields and all parts of the world. Some of these are already in progress; others are ready for development. Many encompass and build on ongoing ISC activities, including the Council's portfolio of international research programmes, scientific committees, networks, data bodies and observing systems.

Call to action: The ISC seeks partnerships with members, with other international scientific organizations, with funders and with stakeholders in the public and private sectors who are inspired by the actions presented in the Plan and who want to join ISC and who share the ambitions captured in the global call. ISC's projects and programmes cover four domains of impact: i) the 2030 Agenda for Sustainable Development; ii) The Digital Revolution; iii) Science in Policy and Public Discourse; and iv) The Evolution of Science and Science Systems.

https://council.science/actionplan/ 